\title{
Visualized Experiment of Bubble Behaviors in a Vertical Narrow Rectangular Channel Under Natural Circulation Condition
}

OPEN ACCESS

Edited by:

Jun Wang,

University of Wisconsin-Madison,

United States

Reviewed by:

Yacine Addad,

Khalifa University, United Arab

Emirates

Claudio Tenreiro,

University of Talca, Chile

*Correspondence:

Meiyue Yan

yanmeiyue@hrbeu.edu.cn

Changqi Yan

changqi_yan@163.com

Specialty section

This article was submitted to Nuclear Energy,

a section of the journal

Frontiers in Energy Research

Received: 09 August 2018

Accepted: 21 September 2018

Published: 23 October 2018

Citation:

Yan $M$, Ren $T$, Chen $K$, Yan C, Yang Y

Tian C, Yang K and Ai D (2018)

Visualized Experiment of Bubble

Behaviors in a Vertical Narrow

Rectangular Channel Under Natural

Circulation Condition.

Front. Energy Res. 6:105.

doi: 10.3389/fenrg.2018.00105

\author{
Meiyue Yan ${ }^{1 *}$, Tingting Ren ${ }^{1}$, Kailun Chen ${ }^{1}$, Changqi Yan ${ }^{1 *}$, Yongyong Yang ${ }^{2}$, \\ Chunping Tian ${ }^{1}$, Kuan Yang ${ }^{1}$ and Dechun $\mathrm{Ai}^{3}$
}

${ }^{1}$ Fundamental Science on Nuclear Safety and Simulation Technology Laboratory, Harbin Engineering University, Harbin, China, ${ }^{2}$ China Nuclear Power Operation Technology Corporation, LTD, Wuhan, China, ${ }^{3}$ School of Mining and Civil

Engineering, Liupanshui Normal University, Liupanshui, China

The characteristics of bubble behavior have been in particular interest for decades due to its significant contribution to understanding the mechanism of heat transfer. In the present work, visualized experiment is conducted to study the bubble characteristics in subcooled flow boiling of a narrow rectangular channel under natural circulation. The experiments were performed at pressures of $0.2 \mathrm{MPa}$, with inlet subcooling ranging from 20 to $60 \mathrm{~K}$ and heat flux ranging from 100 to $300 \mathrm{~kW} / \mathrm{m}^{2}$. A high-speed digital camera is used to capture the pictures of bubble behaviors. A sequence of image processing algorithms is used deal with the original bubble images to get relevant bubble parameters. We observe the whole process of a single sliding bubble lifetime and found most of bubbles slide along the heating surface after detaching the nucleation sites. Five typical sliding bubble growth paths are observed in the present experimental conditions. According to the analysis of the experimental data, it can be found that the liquid subcooling and wall superheat are the main factors that affect the bubble size during sliding in narrow rectangular channel under natural circulation condition. Due to the difference of driving force, the sliding velocity of bubble in forced circulation is always larger than that in natural circulation. At the same time, the bubble velocity changes significantly at different heat flux and shooting location.

Keywords: narrow rectangular channel, natural circulation, subcooled boiling, sliding bubble, bubble behavior

\section{INTRODUCTION}

Flow boiling under natural circulation has been found in many industry applications including nuclear reactor, External Reactor Vessel Cooling (ERVC) (Ha et al., 2004), Passive containment cooling System (PCCS) (Park et al., 2008). In the studies concerning about narrow rectangular channel, more attention has been attracted in sliding bubbles for their great improvements on the capacity of heat transfer. Therefore, study on sliding bubble behaviors is helpful to understand the mechanism of heat transfer in a narrow rectangular channel under natural circulation.

Many researchers have explored sliding bubble characteristics. In the experiment of subcooled flow boiling of water by Prodanovic et al. (Prodanovic et al., 2002), bubble slid for the length of several bubble diameters and migrated toward the bulk fluid. And it was found that bubble sliding is the only way for bubble departure from the nucleation site in microchannel in the study carried 
out by Yin et al. (Yin et al., 2015). Okawa et al. (Okawa et al., 2005a,b) investigated the bubble rise after the departure from a nucleation site. They observed two types of sliding bubble path in vertical upflow boiling: (1) bubbles slide along the wall for long distance without detachment; (2) bubbles detach from the wall after sliding for a certain distance and then migrate toward the bulk liquid. The two types of sliding bubble were also observed by Li et al. (Li et al., 2013) in subcooled upward forced convective flow boiling in narrow channel. There are also many studies on sliding bubble characteristics parameters. From a visualized experiment in a narrow rectangular channel conducted by $\mathrm{Xu}$ et al. (Xu et al., 2010, 2013), we found that the maximum bubble dimension in the direction normal to the heating surface is $>1 \mathrm{~mm}$ in the flow direction, while most bubble diameters are in the range of $0.09-0.4 \mathrm{~mm}$, and the upstream and downstream contact angles were almost equal during sliding process. Chen et al. (Chen et al., 2011) performed a study of vapor bubble behavior under different system pressures in a narrow channel. The sliding bubble size and growth rate decrease with the increase of system pressure. The sliding bubble phenomenon also was found in gas-liquid flow. Zaruba et al. (Zaruba et al., 2007) experimentally and numerically studied the motion of single bubble in a vertical gas-liquid flow, and they found that small bubbles always slide along the wall. However, it is not enough to study the behavior of a single bubble. To understand the bubble population characteristics, Puli et al. (Puli and Kumar, 2012) analyzed the bubble size density distribution under different pressures, and the number of smaller bubbles increase with the increasing pressure.

The mechanism of sliding bubble to enhance surface heat transfer attracts many attentions. Thorncroft et al. (Thorncroft et al., 1998; Thorncroft and Klausner, 1999) conducted experiments in subcooled flow boiling using refrigerant FC-87 in both upward and downward flow. In upward flow, bubble slid along the wall and was not detached from the wall. While in downward flow, bubbles were detached directly or just slid for several millimeters from the nucleation sites, it was found that the heat transfer coefficient in upflow is significantly higher

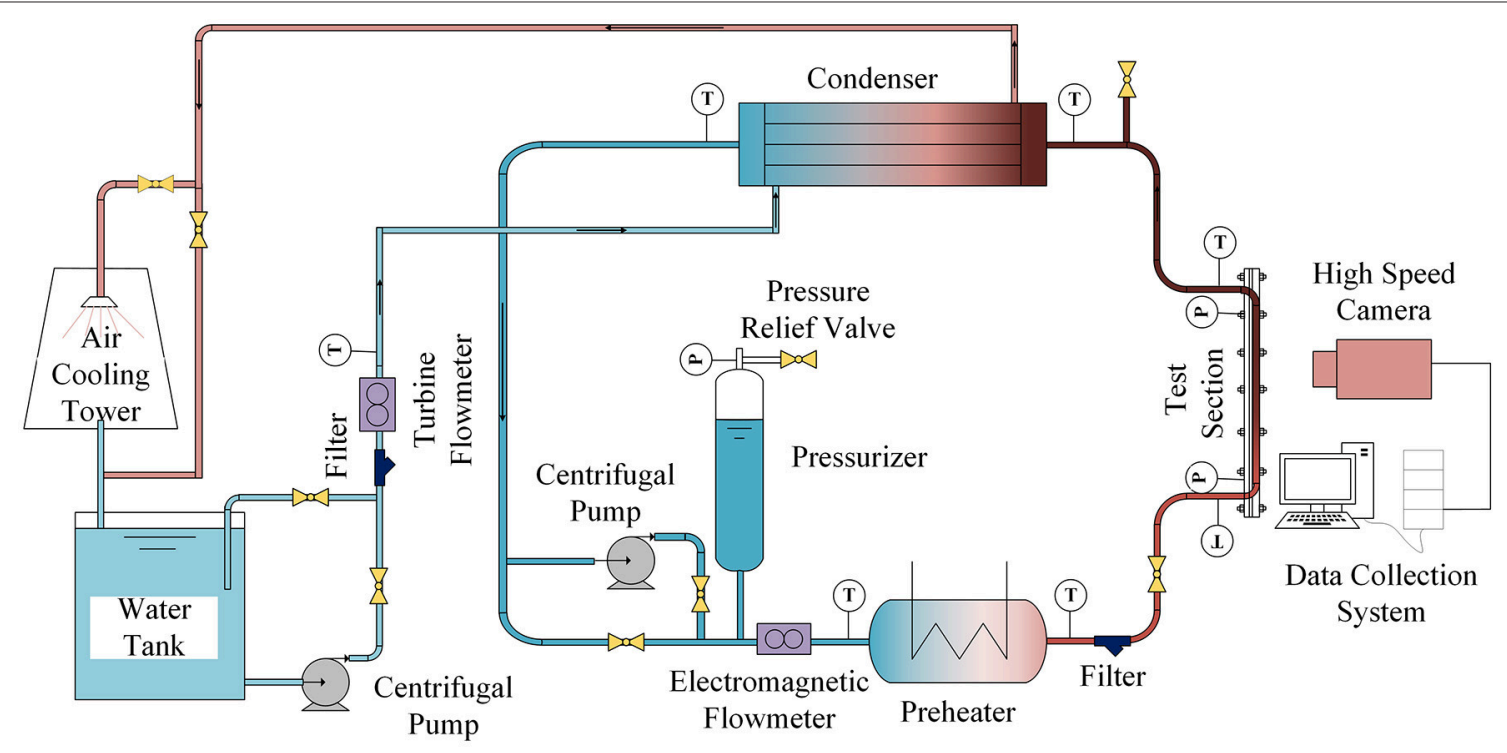

FIGURE 1 | Schematic diagram of experimental loop.

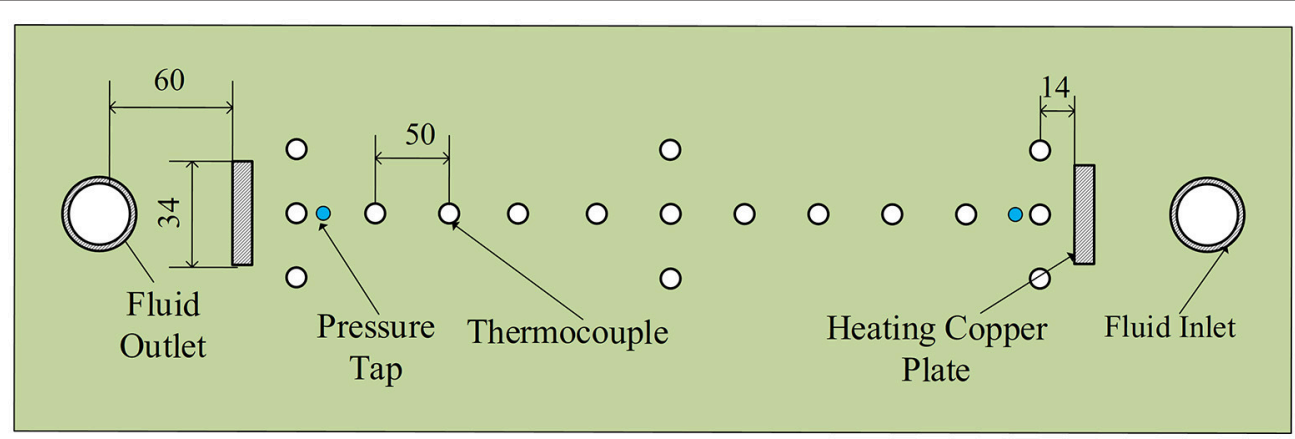

FIGURE 2 | The distribution of temperature points along the heating surface. 
than that in downflow. Thorncroft believed that the reason for this phenomenon is the existence of sliding bubble enhancing the heat transfer. Ozer et al. (Ozer et al., 2011) studied the subcooled nucleate boiling in horizontal narrow channel using $\mathrm{R}-11$ and Novec 649. He found that the position where the bubble first nucleated was caused primarily by sliding bubbles. B. Donnelly et al. (Donnelly et al., 2009), Y. Yan et al. (Yan and Kenning, 1997), and D. K. Hollingsworth (Hollingsworth et al., 2009) also observed bubbles sliding phenomenon on the inclined heated wall. They concluded that the wave behind the sliding bubbles was responsible for the heat transfer enhancement.

Natural circulation is driven by the buoyancy force due to the density gradient in the loop, does not need any moving part. The mass flow rate depends on the operating parameters, and the mass flow rate is lower comparing with forced circulation under same conditions. The bubble behaviors are various and complicated under natural circulation. At the same time, natural circulation itself is related to bubble behavior. Most of the researches were carried out under forced convective flow, while the sliding bubbles characteristics under natural circulation was less explored. The mechanism of sliding bubble in natural circulation has not been thoroughly understood. Only Zhou et al. (Zhou et al., 2013) studied the single bubble characteristics under natural circulation. Compared with the experimental results under the forced circulation with same thermal parameters, the growth time was longer, the departure velocity was higher and the waiting time was shorter. The objective of the present work is to investigate sliding bubble characteristics in upward subcooled flow boiling in a vertical narrow rectangular channel under natural circulation. In order to describe the features.

\section{EXPERIMENTAL METHODS}

In order to study bubble behaviors in a narrow rectangular channel under natural circulation condition, an experimental loop shown in Figure $\mathbf{1}$ is designed and constructed. The experimental loop mainly consists of four major parts, including a pressurizer, a preheater, a test section and a condenser. The pressurizer is connected with nitrogen cylinder to keep the system pressure at $0.2 \mathrm{MPa}$. The $40 \mathrm{~kW}$ preheater is used to control the water temperature at the inlet of the test section. Two $\mathrm{K}$ type shield thermocouples with an accuracy of $\pm 0.5 \mathrm{~K}$ are used to measure the inlet and outlet temperature of the preheater. After heated by the preheater, the water is delivered to the test section. After exiting the test section, the work liquid is sent to a condenser. The condenser is the only heat sink of the loop where the fluid temperature is reduced before returning to the preheater. To measure the temperature along the test section, $17 \mathrm{~N}$-type shielded thermocouples are arranged along the flow channel, and the temperature distribution points are illustrated in Figure 2.

The setup of visualization system is shown in Figure 3. A high speed camera is used to record the sliding bubble process. The

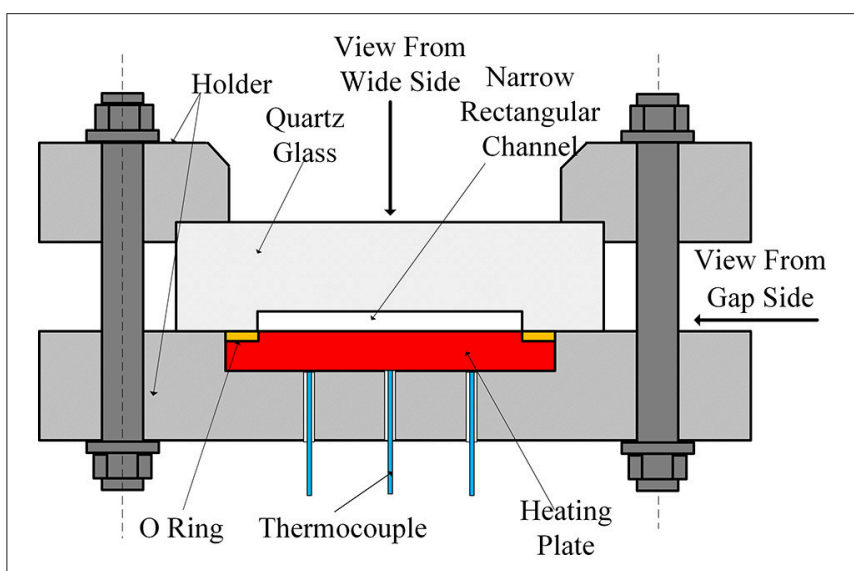

FIGURE 4 | Cross sectional view of test section.

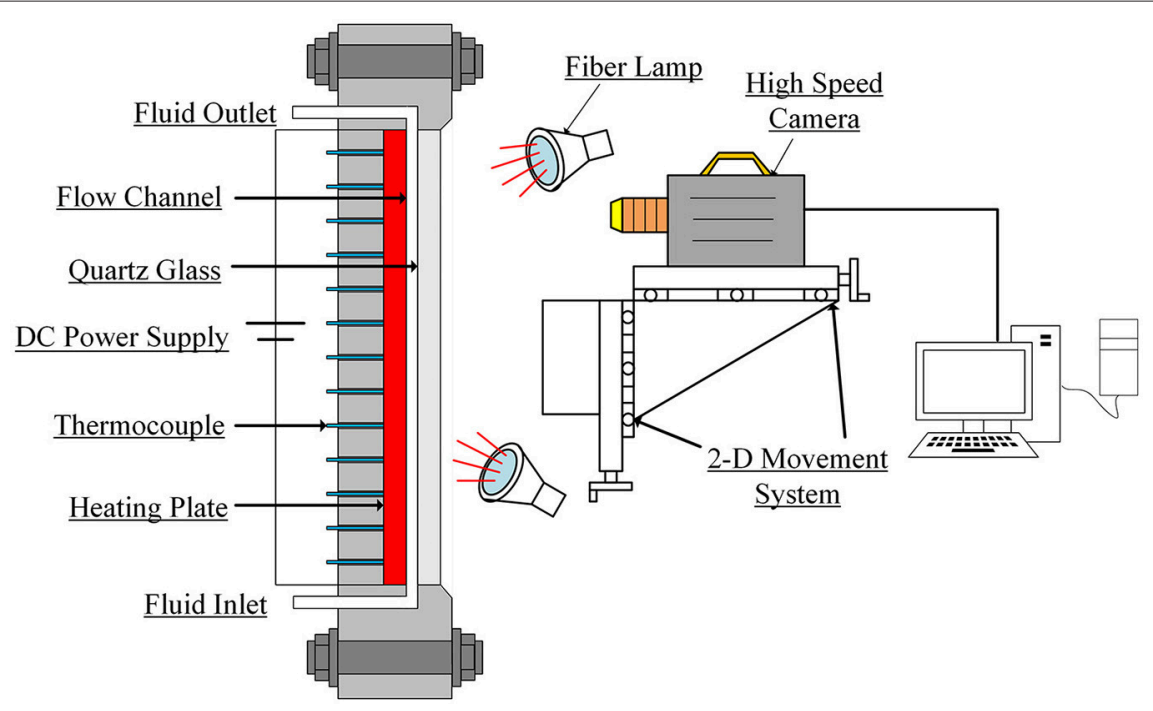

FIGURE 3 | Schematic of visualization system. 
camera is mounted on a 2-D traverse system, which can be moved vertically and horizontally. The camera is located at different height of channel to record the bubble behaviors under each operating condition. The height is the vertical distance between the center of camera lens and location of fluid inlet. Two $150 \mathrm{~W}$ fiber lights are placed before the test section in order to provide sufficient light for shooting.

Figure 4 shows cross section of the test section. The total heating length is $550 \mathrm{~mm}$. The test section is made up of stainless steel and glass. To enable visualization of the bubble behaviors, the channel is designed to be single-side heated. The stainless heater plate is heated by a DC power with capacity of 2,000 A/50 V.

Deionized water is used as working fluid. In order to avoid the effect of dissolved non-condensable gases in the water on experimental phenomena, the water kept boiling by preheater and test section for degassing before the experiment. The non-condensation is released from the valve on the top of experimental loop. After degassing, the secondary cooling was activated to create density difference between the riser and downcomer of primary loop. Then centrifugal pump is shut off in order to switch the working mode from forced circulation to natural circulation. Main parameter ranges are summarized in Table $\mathbf{1 .}$

In the experiment, the filming frame rate and resolution are set to $5,000 \mathrm{fps}$ and $1,240 \times 1,240$ pixels. The corresponding physical scale of the view window is about $20 \times 20 \mathrm{~mm}^{2}$. The uncertainty for locating the position is within \pm 2 pixels, thus the maximum error of bubble location is limited to $\pm 0.04 \mathrm{~mm}$.

The uncertainties of main parameters are summarized in Table 2 .

TABLE 1 | Experimental parameter ranges.

\begin{tabular}{lc}
\hline Experimental parameter & Experimental range \\
\hline System pressure $\left(P_{\text {sys }}\right)$ & $0.2 \mathrm{MPa}$ \\
Inlet fluid subcooling $\left(\Delta T_{\text {in,sub }}\right)$ & $20-60 \mathrm{~K}$ \\
Heat flux of the heating surface $(q)$ & $100-300 \mathrm{~kW} / \mathrm{m}^{2}$ \\
Mass flux $(G)$ & $280-450 \mathrm{~kg} /\left(\mathrm{m}^{2} \cdot \mathrm{s}\right)$ \\
$\mathrm{Nu}$ & $26-80$ \\
$\mathrm{Re}$ & $3,578-7,290$ \\
\hline
\end{tabular}

TABLE 2 | Estimated errors of main measurement parameters.

\begin{tabular}{lc}
\hline Measured parameters & Maximum error $( \pm)$ \\
\hline Time & $10^{-6} \mathrm{~s}$ \\
Length & $0.5 \mathrm{~mm}$ \\
Heat flux & $0.5 \%$ \\
Wall temperature & $0.56 \mathrm{~K}$ \\
Calibration of the image & $0.016 \mathrm{~mm} / \mathrm{pixel}$ \\
Bubble location & $0.04 \mathrm{~mm}$ \\
Bubble diameter & $0.08 \mathrm{~mm}$ \\
Bubble velocity & $0.04 \mathrm{~m} / \mathrm{s}$
\end{tabular}

\section{RESULTS AND DISCUSSION Observation of Single Sliding Bubble Behaviors}

The growth behavior of single bubble is a complex phenomenon, which has a coupling effect to the wall temperature field, fluid temperature field, fluid velocity, etc. Figure 5 shows the whole process of a single sliding bubble lifetime. Because of the restriction of narrow channel, there will more sliding bubbles generated on the heating surface. The mass existence of sliding bubble will increase heat transfer coefficient strongly. A whole sliding bubble cycle is mainly divided into two stages: growth stage and waiting stage. The growth stage represents the time during a bubble still attached to its nucleation site. In general, a bubble generates at a nucleation site then grows in the radial direction by adsorbing heat from superheated liquid layer between the bubble and heating wall, and then departs from the nucleation site after its diameter reaches a critical value. The waiting stage describes the time after bubble departs from its site until the next bubble forms at the same nucleation site. After normalizing the bubble diameter, it is found that the in natural circulation the bubble growth time accounts for a larger proportion in bubble cycle than in the forced circulation (Zhou et al., 2013).

The bubble size is determined by the balance of the evaporation rate at the bubble interface in the superheated liquid layer and the condensation at the interface surrounded by the subcooled bulk liquid. When the evaporation rate not equal to the condensation rate, the bubble diameter will change. Consecutive images of bubbles obtained in the experimental condition of $\Delta \mathrm{T}_{\text {in,sub }}=41 \mathrm{~K}, q=141 \mathrm{~kW} / \mathrm{m}^{2}$, five typical bubble growth are shown in Figure 6. The image sequences of bubbles 1-5 are shown on Figures 7-11, respectively. These bubbles are obtained from the same shooting window, but due to the differences of these bubbles in each picture, in order to highlight the bubble shapes and facilitate the acquisition of subsequent bubble parameters, the operations performed in the image processing software are different, thus the backgrounds seem to be different. In particular, the bubble in Figure $\mathbf{1 0}$ disturb the surrounding liquid, which cause the background to be different greatly from other figures. Figures 7, 8 show the growth characteristics of two typical types of sliding bubbles in narrow rectangular channel. The diameter change rate of bubble 1 is rapidly, while the bubble sliding distance and survival time are short. By observing the bubble videos, most sliding bubbles were similar to bubble 3 shown in Figure 9. The diameter of these bubble keep nearly constant during its sliding stage, and the sliding velocity is constant during the sliding process. The bubble diameter shown in Figure 10 gradually decrease, such bubbles will eventually disappear which means the condensation in advantage all the time. There is also a kind of bubble shown in Figure 11. After the detachment, the bubble diameter will decrease slowly due to the subcooled bulk fluid. However, this kind of bubbles does not collapse in the subcooled liquid but reattaches to the heating wall, then the bubble diameters begin to increase again. The reason for this type bubble existing is that the bubble departing from the heating wall for a period of time then reattaching to the wall due 


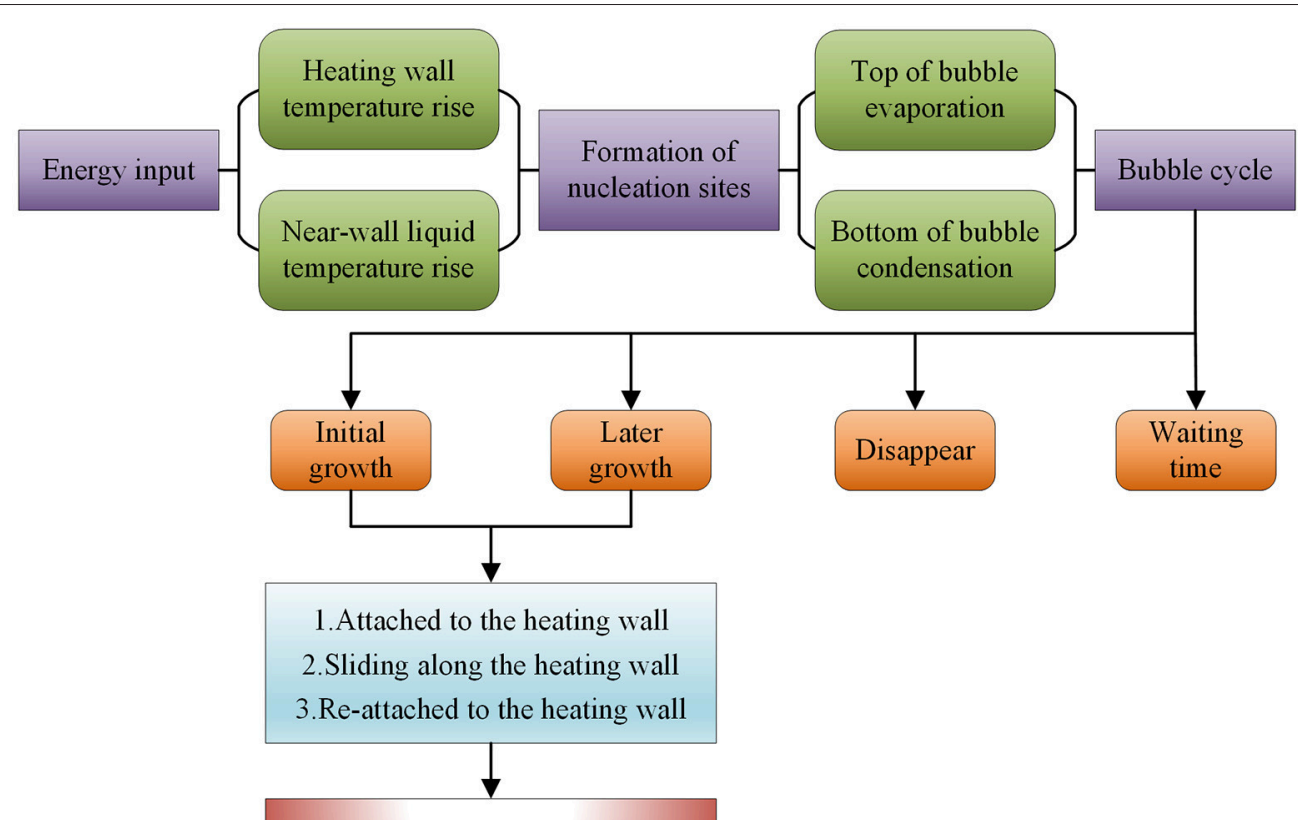

Heat transfer and flow is affected

FIGURE 5 | The cycle of single sliding bubble.

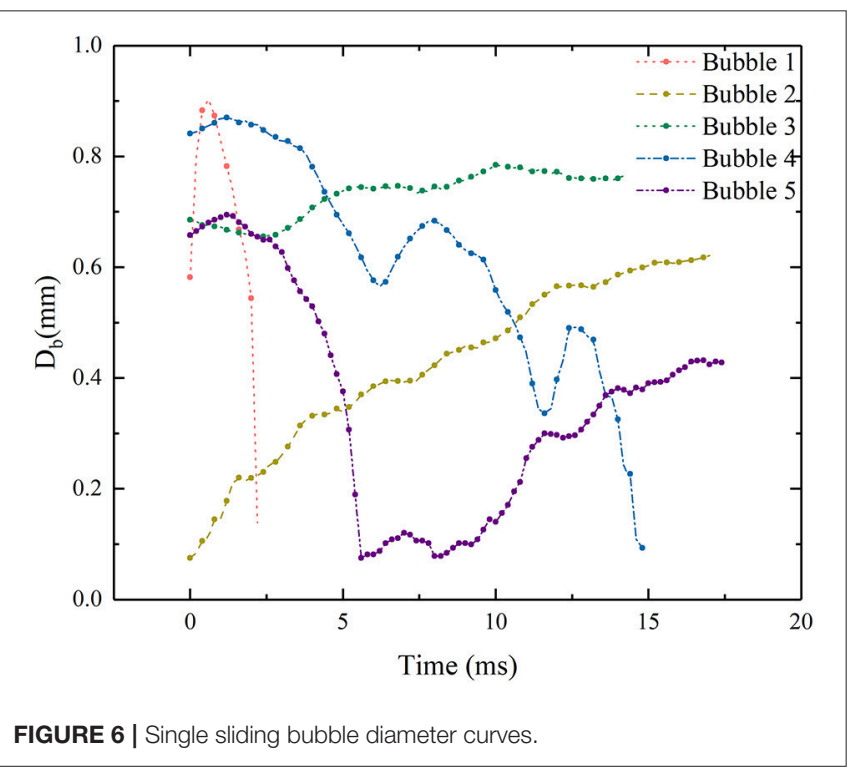

to the limitation of the gap size of narrow rectangular channel. This kind of bubble is called bouncing bubble, and this kind of bubbles were clearly observed as a typical bubble behaviors in the present experiments.

\section{Observation of Boiling Phenomenon Under Natural Circulation}

Massive amounts of bubble image data are obtained in the experiment. Therefore, a batch-processing method is developed to deal with the bubble images. The pre-processing of bubble images is conducted by Image Pro Plus 6.0, by which a sequence of digital image processing algorithms is applied to deal with the original video in order to extract bubble location and shape information. Based on the image processing results, the bubble diameter of each frame existed in the filming window can be obtained. For the average diameter of a large number of bubbles, the formulas can be calculated as followed

$$
D_{\text {ave }}=\frac{1}{\sum_{i=1}^{m} n_{i}}\left(\sum_{i=1}^{m} \sum_{j=1}^{n_{i}} D_{e, j}\right)
$$

in the formula, the $D_{\text {ave }}$ is the average diameter of all the bubble existing in the filming window. $m$ represents the number of frames, and $n_{\mathrm{i}}$ represents the number of bubbles at each frame.

The mean sliding diameters under different heights and heat flux are depicted in Figure 12. Each point value is the mean value of all captured bubble diameters in the filming. It can be seen from the figure that when the heat flux is less than a certain value, the mean bubble diameter increases with increasing heat flux. This is because an increase in the heat flux will cause an increase in evaporation at the bottom of the bubble, resulting an increase in the bubble diameter. When the heat flux exceed a certain value, the mean diameters change randomly. It is mainly attributed to two reasons: the bubble size prefer to oscillate when the heat flux is high. At the same time, the number of nucleation sites on the heating surface is increased, which are favorable to the generation of both big bubbles and small bubble. This results in a random change in the mean bubble diameter as heat flux increases. 


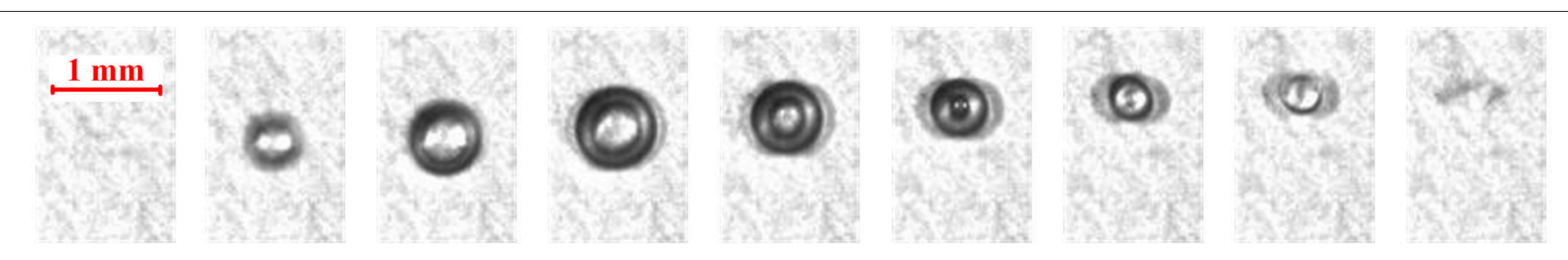

FIGURE 7 | Image sequence of bubble 1.

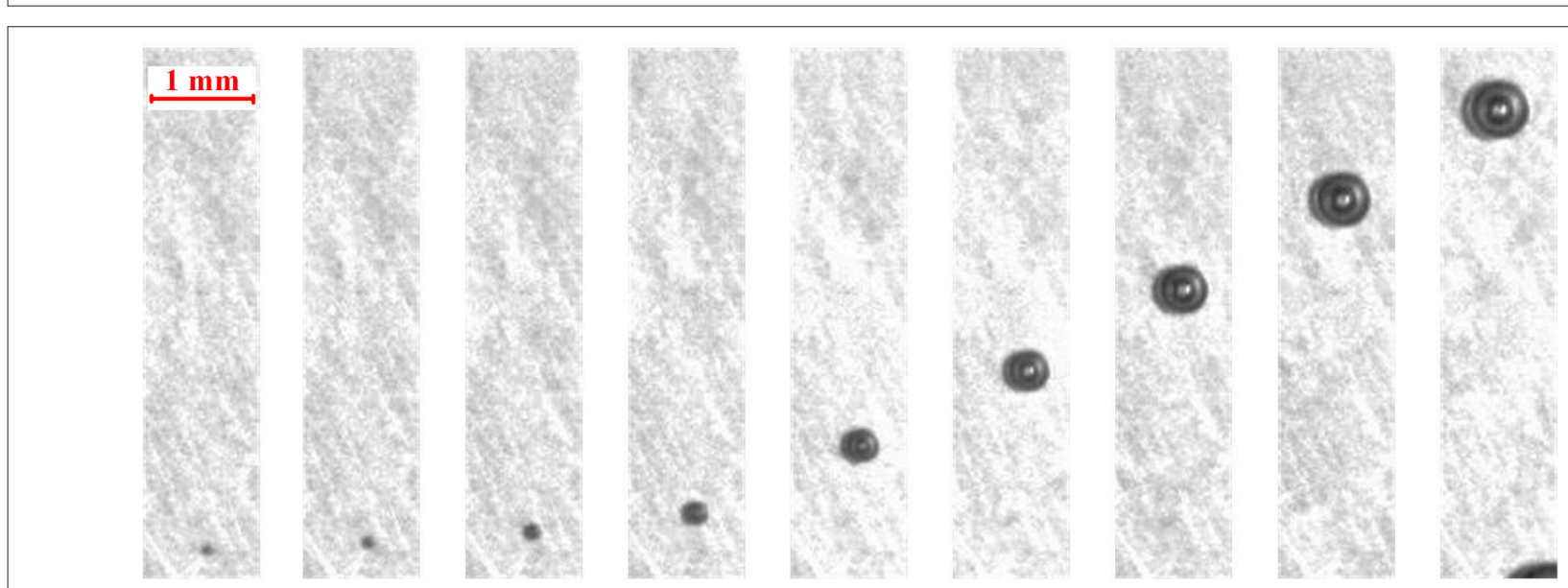

FIGURE 8 | Image sequence of bubble 2.

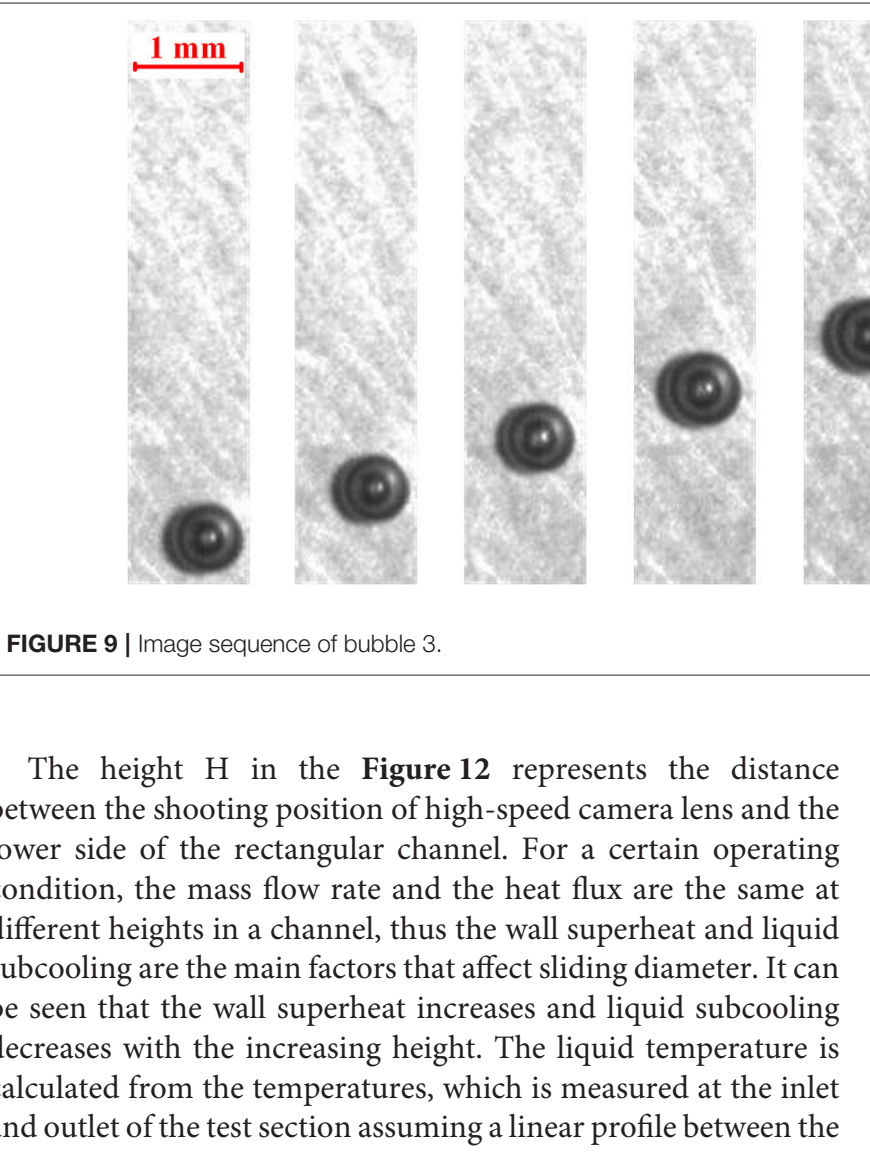

two temperature measurement points. Zhang et al. (Zhang et al., 2015) had reported that the bulk flow temperature of subcooled boiling changes almost linearly along the flow direction with the outlet void fraction about 50\%. From the bubble filming videos, we can find the void fraction is much $<50 \%$ in the experiment, thus the assumption is reasonable. The liquid layer evaporation rate under the bubble increases with the increase of wall superheat, and the bulk flow condensation rate decreases with the decease of liquid subcooling. Both of the two factors above are benefits to the sliding diameter increase in the channel. 

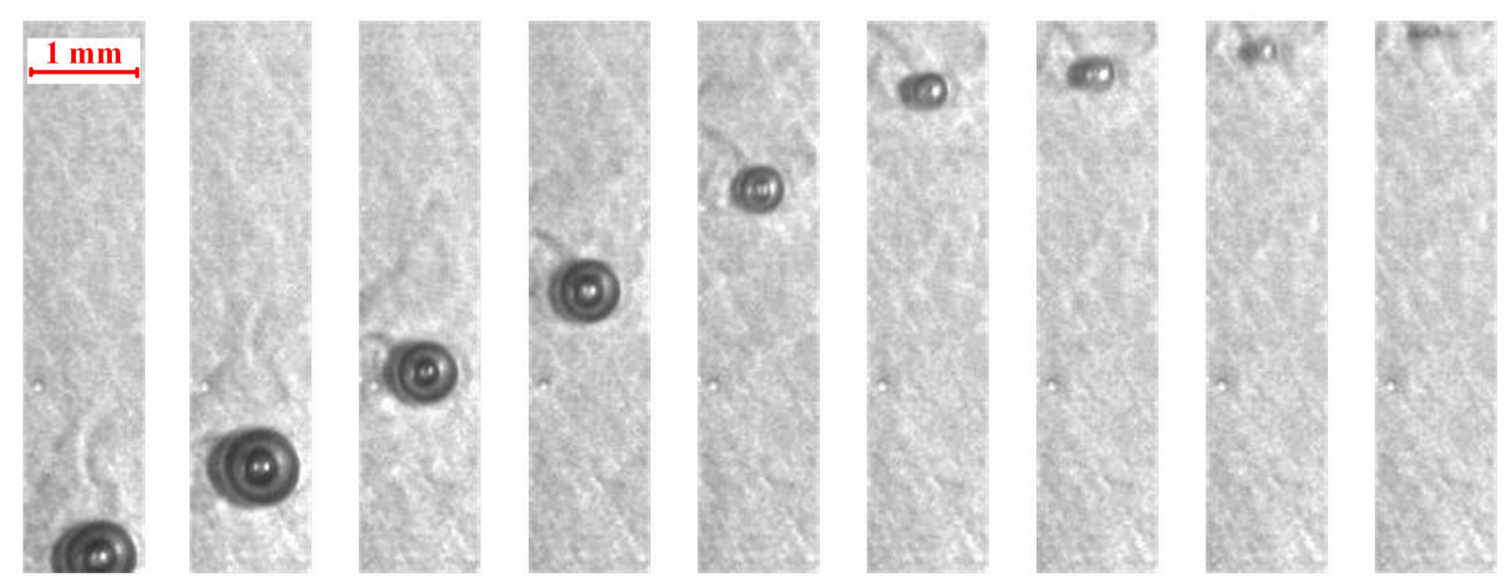

FIGURE 10 | Image sequence of bubble 4.
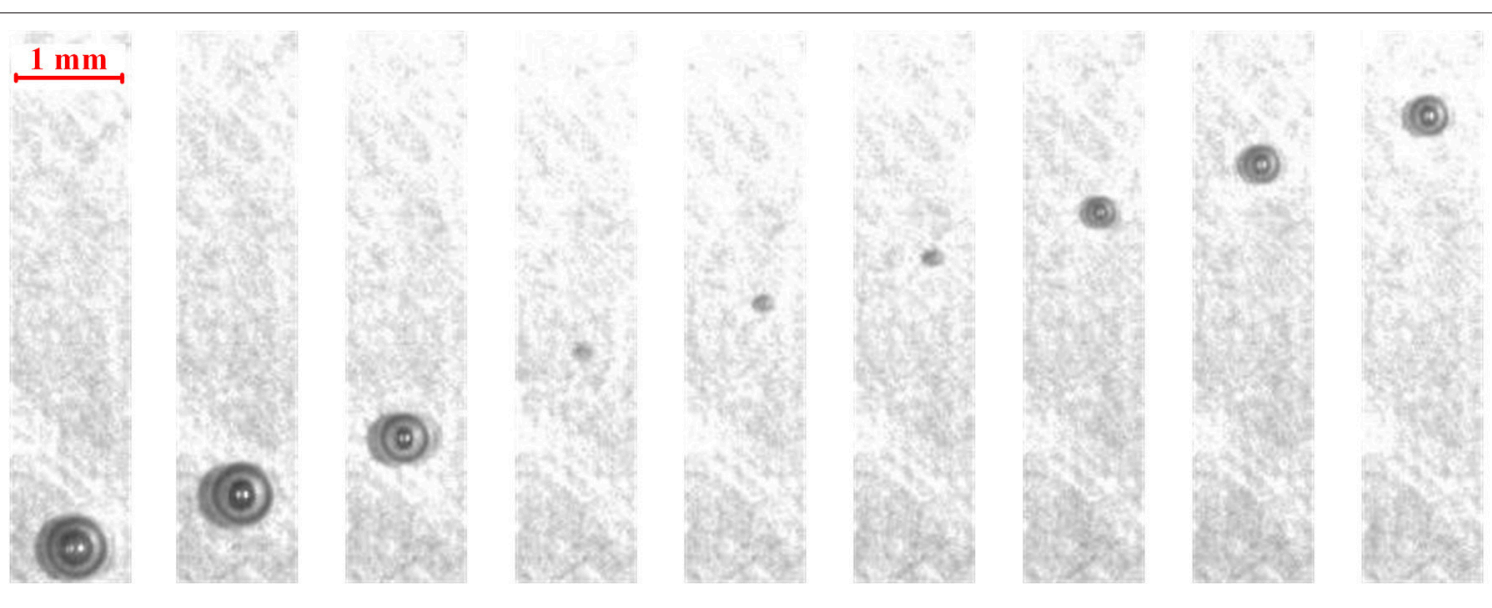

FIGURE 11 | Image sequence of bubble 5.

\section{Comparison Between Natural Circulation and Forced Circulation}

It can be seen from the video that the bubble movement in horizontal direction can be negligible compared with that in vertical direction. So the bubble velocity is calculated according the successive images in the vertical direction. The velocity of the centroid of a bubble represents its velocity can be given by

$$
V_{e}=\frac{y_{t_{2}}-y_{t_{1}}}{t_{2}-t_{1}} C
$$

where $y$ is the bubble coordinate in vertical direction; $t_{2}-t_{1}$ denotes the time internal of two images; $\mathrm{C}$ is the calibration of bubble image.

$$
V_{\text {ave }}=\frac{1}{\sum_{i=1}^{m} n_{i}}\left(\sum_{i=1}^{m} \sum_{j=1}^{n_{i}} V_{e, j}\right)
$$

To figure out the differences of sliding bubble under natural circulation and forced circulation, the comparison of mean sliding bubble velocity is shown in Figure 13. It can be seen that there are obvious differences of sliding bubble diameter between natural and forced circulation while the operating parameters are the same in the test section. We can found the mean velocity of sliding bubble in forced circulation is larger than in natural circulation. This is mainly because the circulation of the working medium in the forced circulation depends on the drive of the main pump in the experimental loop; while the driving force in natural circulation is the density difference between riser and down-comer in experimental loop. Under the same operating condition, the drag force of the liquid flow on the sliding bubble in forced circulation is larger than that in natural circulation, thus the bubble velocity in the forced circulation is generally larger than the natural circulation. The $\mathrm{L}_{\mathrm{x}} / \mathrm{L}_{\text {tot }}$ in Figure 13 represents the ratio of the height of the camera to the length of the entire channel. Since the bubble is subjected to buoyancy force and drag force, it is in acceleration state all the time, so the bubble velocity will increase as the sliding distance increases. For the same reason, the location of ONB will moves down when the heat flux increases. In other words, the bubble sliding distance becomes longer when the shooting position is unchanged. The 


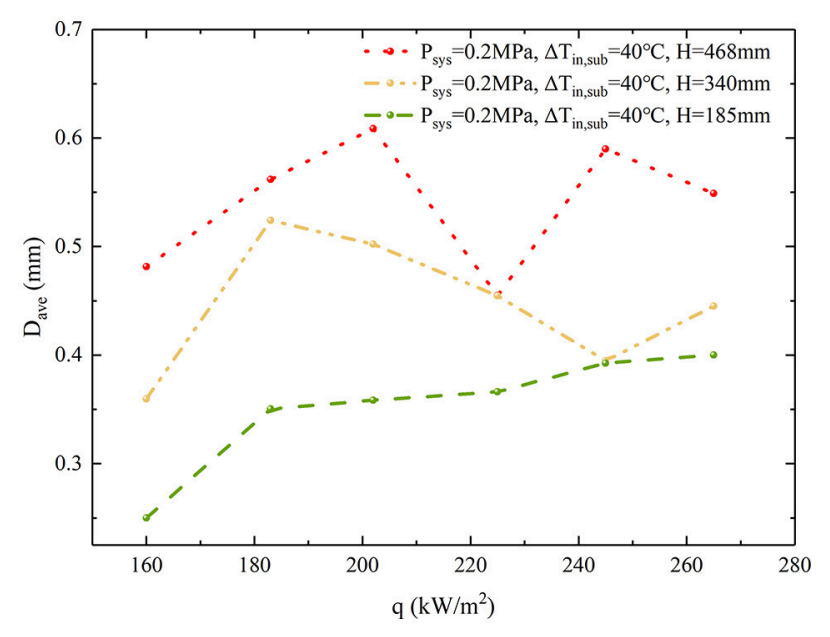

FIGURE 12 | The mean diameter of sliding bubble.

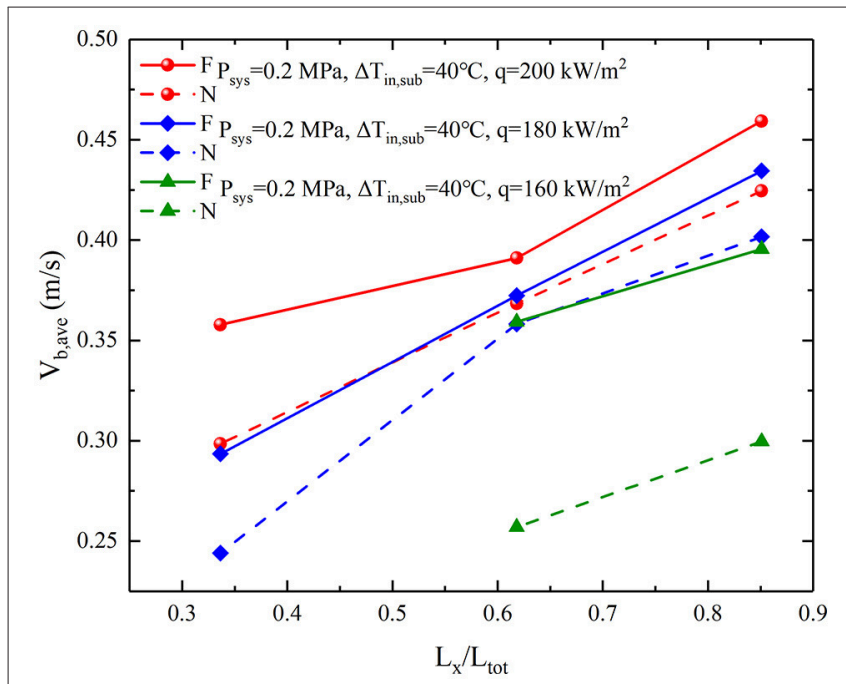

FIGURE 13 | The comparison between natural circulation and forced circulation of bubble velocity.

other reason is the heat flux $\left(<200 \mathrm{~kW} / \mathrm{m}^{2}\right)$ will make the bubble diameters larger, and the increased bubble diameter can result in a larger drag force acting on the bubble, which can cause an acceleration of bubble velocity.

\section{REFERENCES}

Chen, D., Pan, L., Yuan, D., Zhang, H., Xu, J., Huang, Y., et al. (2011). The natural of bubble growth under different system pressures in a narrow channel. Nucl. Eng. Des. 241 785-791. doi: 10.1016/j.nucengdes.2010.12.013

Donnelly, B., O'Donovan, T. S., and Murray, D. B. (2009). Surface heat transfer due to sliding bubble motion. Appl. Therm. Eng.29, 1319-1326. doi: 10.1016/j.applthermaleng.2008.09.002

Ha, K. S., Park, R. J., Kim, H. Y., Kim, S. B., and Kim, H. D. (2004). A study on the two-phase natural circulation flow through the

\section{CONCLUSION}

The sliding bubble behaviors in a narrow vertical channel under natural circulation subcooled flow boiling condition was studied. In the experiment, water is used as working medium. The test pressure is $0.2 \mathrm{MPa}$, the inlet liquid subcooling ranged from 20 to $60 \mathrm{~K}$, and the heat flux varied from 100 to $300 \mathrm{~kW} / \mathrm{m}^{2}$. A highspeed camera was used to capture the behaviors of sliding bubble. The main conclusions of the present work can be expressed as:

(1) Bubble always slide along the vertical surface after departing from the nucleation site in a narrow rectangular channel. The sliding bubble cycle is described, and five typical kinds of sliding bubbles can be observed this experiment.

(2) The differences in shooting position mainly reflects the differences of liquid subcooling, and the liquid subcooling and heat flux have significant influence on the bubble diameters.

(3) The mean velocity of sliding bubble in forced circulation is larger than in natural circulation. At the same time, the bubble velocity changes significantly at different heat flux and shooting location under both forced and natural circulation.

\section{AUTHOR CONTRIBUTIONS}

MY carried out experiments and analyzed the experimental results, as well as the writing of paper. TR and $\mathrm{KC}$ assisted in experimental work and dealt with the experimental data. CY and DA gave the guideline of this research and modified the language of manuscript. YY developed tools to analyze the bubble behaviors. CT and KY designed the experimental loop and guided the experimental work.

\section{ACKNOWLEDGMENTS}

The authors greatly appreciate support of the Natural Science Foundation of China (Grant No. 11675045). The author thanks to the Key Supported Discipline of Guizhou Provence (Qian Xuewei He Zi ZDXK[2016]24), 2011 Collaborative Innovation Center of Guizhou Province (Qian Jiao he xietongchuangxin zi [2016]02). Additionally, the authors are thankful for the support of the Fundamental Science on Nuclear Safety and Simulation Technology Laboratory, Harbin Engineering University, China.

annular gap between a reactor vessel and insulation system. Int Comm. Heat Mass Transfer 31, 43-52. doi: 10.1016/S0735-1933(03) 00200-8

Hollingsworth, D. K., Writte, L. C., and Figueroa, M. (2009). Ehancement of heat transfer behind a sliding bubble. ASME J. Heat Transfer 131, 121005-1-1210059. doi: 10.1115/1.3216039

Li, S., Tan, S., Xu, C., Gao, P., and Sun, L. (2013). An experimental study of sliding bubble characteristics in narrow channel. Int. J. Heat Mass Transfer 57, 89-99. doi: 10.1016/j.ijheatmasstransfer.2012. 10.002 
Okawa, T., Ishida, T., Kataoka, I., and Mori, M. (2005a). An experimental study on bubble rise path after departure from a nucleation site in vertical upflow boiling. Exp. Therm. Fluid Sci. 29, 287-294. doi: 10.1016/j.expthermflusci.2004.05.010

Okawa, T., Ishida, T., Kataoka, I., and Mori, M. (2005b). Bubble rise characteristics after the departure from a nucleation site in vertical upflow boiling of subcooled water. Nucl. Eng. Des. 235, 1149-1161. doi: 10.1016/j.nucengdes.2005.02.012

Ozer, A. B., Oncel, A. F., Hollingsworth, D. K., and Writte, L. H. (2011). The effect of sliding bubbles on nucleat boiling of a subcooled liquid flowing in a narrow channel. Int. J. Heat Mass Transfer54, 1930-1940. doi: 10.1016/j.ijheatmasstransfer.2011.01.010

Park, H., Choi, K., Cho, S., Yi, S. J., Park, C. K., Chung, M. K., et al. (2008). Experimental study on the natural circulation of a passive residual heat removal system for an integral reactor following a safety related event. Ann. Nucl. Eng.35, 2249-2258. doi: 10.1016/j.anucene.2008.09.006

Prodanovic, V., Fraster, D., and Salcudean, M. (2002). Bubble behavior in subcooled flow boiling of water at low pressure and low flow rate. Int. J. Multiphase Flow 28 1-19. doi: 10.1016/S0301-9322(01)00058-1

Puli, U., and Kumar, R. A. (2012). Parametric effect of pressure on bubble size distribution in subcooled flow boiling of water in a horizontal annulus. Exp. Therm. Fluid Sci. 37, 164-170. doi: 10.1016/j.expthermflusci.2011.11.001

Thorncroft, G. E., and Klausner, J. F. (1999). The influence of vapor sliding bubble on forced convection boiling heat transfer. J. Heat Transfer 121, 73-79. doi: $10.1115 / 1.2825969$

Thorncroft, G. E., Klausner, J. F., and Mei, R. (1998). An experimental investigation of bubble growth and detachment in vertical upflow and downflow boiling. Int. J. Heat Mass Transfer 41, 3857-3871. doi: 10.1016/S0017-9310(98) 00092-1

Xu, J., Chen, B., Huang, Y., Yan, X., and Yuan, D. (2013). Experimental Visualization of sliding bubble dynamics in a vertical narrow rectangular channel. Nucl. Eng. Des. 261, 156-164. doi: 10.1016/j.nucengdes.2013. 02.055
Xu, J., Chen, B., and Wang, X. (2010). Prediction of sliding bubble velocity and mechanism of sliding bubble motion along the surface. J. Enhanced Heat Transfer 17, 111-124. doi: 10.1615/JEnhHeatTransf.v17.i2.10

Yan, Y., and Kenning, D. (1997). Sliding and sticking vapor bubbles under inclined plane and curved surfaces. Int. J. Refrig. 20, 583-591. doi: 10.1016/S0140-7007(97)00066-2

Yin, L., Li, J., and Xu, M. (2015). Experimental investigation on sliding bubble during subcooled flow boiling in microchannel. Exp. Therm. Fluid Sci.68, 435-441. doi: 10.1016/j.expthermflusci.2015.05.010

Zaruba, A., Lucas, D., Prasser, H. M., and Höhne, T. (2007). Bubble-wall interactions in a vertical gas-liquid flow: bouncing sliding and bubble deformations. Chem. Eng. Sci.62, 1591-1605. doi: 10.1016/j.ces.2006.11.044

Zhang, R., Cong, T., Tian, W., Qiu, S., and Su, G. (2015). Effects of turbulence models on forced convection subcooled boiling in vertical pipe. Ann. Nucl. Eng.80, 293-302. doi: 10.1016/j.anucene.2015.01.039

Zhou, T., Duan, J., Hong, D., Ping, L., Cheng, S., Yanping, H., et al. (2013). Characteristics of a single bubble in subcooled boiling region of a narrow rectangular channel under natural circulation. Ann. Nuc. Eng. 57, 22-31. doi: 10.1016/j.anucene.2013.01.052

Conflict of Interest Statement: The authors declare that the research was conducted in the absence of any commercial or financial relationships that could be construed as a potential conflict of interest.

Copyright (C) 2018 Yan, Ren, Chen, Yan, Yang, Tian, Yang and Ai. This is an openaccess article distributed under the terms of the Creative Commons Attribution License (CC BY). The use, distribution or reproduction in other forums is permitted, provided the original author(s) and the copyright owner(s) are credited and that the original publication in this journal is cited, in accordance with accepted academic practice. No use, distribution or reproduction is permitted which does not comply with these terms. 


\section{NOMENCLATURE}

$\begin{array}{llll}D & \text { Bubble diameter } & \text { Subscripts } & \\ T & \text { Temperature } & \text { ave } & \text { average value } \\ V & \text { Bubble velocity } & \text { tot } & \text { total } \\ C & \text { Calibration of the image } & \text { in } & \text { inlet } \\ H & \text { Height } & \text { out } & \text { outlet } \\ W & \text { Width of the channel } & \text { l } & \text { liquid } \\ L & \text { Length of the channel } & v & \text { vapor } \\ G & \text { Mass flow } & \text { ave } & \text { average value } \\ Q & \text { Heating power } & \text { sub } & \text { subcooling } \\ P & \text { Pressure } & b & \text { bubble } \\ t & \text { Time } & f & \text { fluid } \\ q & \text { Heat flux } & w & \text { wall } \\ m & \text { Number of frames } & m & \text { maximum } \\ n & \text { Number of bubbles } & & \\ \text { Re } & \text { Reynolds number } & & \\ \mathrm{Nu} & \text { Nusselt number } & & \end{array}$

